\title{
COPROLITOS DE CAMÉLIDOS DEL HOLOCENO COMO INDICADORES PALEOAMBIENTALES
}

\author{
NADIA J. VELÁZQUEZ", LIDIA S. BURRY", MARIA V. MANCINI"** Y MARTÍN H. FUGASSA"***
}

\begin{abstract}
RESUMEN
El estudio de coprolitos permite abordar aspectos ecológicos y culturales de poblaciones pasadas, como reconstrucciones del paleoambiente, de paleodietas, inferir estacionalidad en el uso de los recursos y situaciones de parasitismo. El objetivo de este trabajo es reconocer el aporte del análisis polínico de coprolitos para las reconstrucciones paleoambientales e identificar posibles ítems de la dieta de guanacos del Holoceno del área cercana al sitio Cerro Casa de Piedra 7 (Parque Nacional Perito Moreno, Santa Cruz, Argentina). Se analizó el contenido polínico de 15 coprolitos de guanaco provenientes de 7 capas arqueológicas entre $9.640 \pm 190$ y $5.400 \pm 64{ }^{14} \mathrm{C}$ años AP. La extracción polínica se llevó a cabo mediante acetólisis y se realizó la determinación y recuento bajo microscopio óptico. Se registró la presencia de tejido vegetal y de restos de parásitos. Se comparó el espectro polínico de los coprolitos con el espectro de los sedimentos y se realizaron análisis estadísticos. Los tipos polínicos dominantes fueron: Nothofagus, Empetrum rubrum, Asteraceae subfam. Asteroideae y Nassauvia, Poaceae y Caryophyllaceae. Los conjuntos polínicos de coprolitos y sedimentos contemporáneos presentan similitudes en algunos casos y diferencias en proporciones o en composición en otros. Las similitudes encontradas entre coprolitos y sedimentos permiten inferir que el polen de los coprolitos refleja los taxones dominantes de la vegetación, por el contrario cuando hay mayor abundancia de ciertos tipos polínicos en los coprolitos que en los sedimentos, podría deberse a que el polen de los coprolitos está sesgado con sobrerrepresentaciones de los ítems preferidos por el guanaco, mientras que si la abundancia es mayor en los sedimentos que en los coprolitos, podría deberse a que las plantas consumidas no estaban en su período de floración. Los resultados de este trabajo muestran el valor de los coprolitos como indicadores paleoambientales y aportan datos para la reconstrucción paleoambiental y de dieta de los guanacos.
\end{abstract}

PALABRAS CLAVES: coprolitos, camélidos, paleoambiente, Patagonia, polen.

* CIC - Laboratorio de Palinología. Grupo de Investigación Palinología y Bioantropología, Departamento de Biología, Facultad de Ciencias Exactas y Naturales, Universidad Nacional de Mar del Plata. Funes 3250 (CP 7600). Mar del Plata, Buenos Aires, Argentina.e-mail: nvelazquez@mdp.edu.ar

* UNMdP - Laboratorio de Palinología. Grupo de Investigación Palinología y Bioantropología, Departamento de Biología, Facultad de Ciencias Exactas y Naturales, Universidad Nacional de Mar del Plata. Funes 3250 (CP 7600). Mar del Plata, Buenos Aires, Argentina. e-mail: lburry@mdp.edu.ar

*** UNMdP - Laboratorio de Palinología. Grupo de Investigación Palinología y Paleoecología, Departamento de Biología, Facultad de Ciencias Exactas y Naturales, Universidad Nacional de Mar del Plata. Funes 3250 (CP 7600). Mar del Plata, Buenos Aires, Argentina.e-mail: mumancin@mdp.edu.ar

*s* CONICET - Laboratorio de Paleoparasitología. Departamento de Biología, Facultad de Ciencias Exactas y Naturales, Universidad Nacional de Mar del Plata. Funes 3250 (CP 7600). Mar del Plata, Buenos Aires, Argentina. e-mail: mfugassa@mdp.edu.ar 


\title{
CAMELID COPROLITES FROM THE HOLOCENE AS PALEOENVIRONMENTAL INDICATORS
}

\begin{abstract}
The study of coprolites permits to deal with ecological and cultural aspects of past populations, such as palaeoenvironmental reconstructions, palaeodiets, inferences related to the use of resources and parasitism status. The objective of this work is the recognition of the contribution of studies of pollen in coprolites to the palaeoenvironmental reconstructions, and the identification of probable items in the diet of guanacos living during the Holocene in the area near the site Cerro Casa de Piedra 7 (Perito Moreno National Park, Santa Cruz, Argentina). The pollen content of 15 coprolites of guanacos coming from seven archaeological layers dated by ${ }^{14} \mathrm{C}$ and resulting in ages between $9.640 \pm 190$ years $\mathrm{BP}$ and 5.400 \pm 64 years BP were analysed. Pollen extraction was performed through acetolysis, and determination and counting under optical microscope. The presence of plant tissue and parasite remains was recorded. The coprolite pollen spectrum was compared with the sediment spectrum, and statistical analyses were conducted. The dominant pollen types were: Nothofagus, Empetrum rubrum, Asteraceae subfam. Asteroideae and Nassauvia, Poaceae and Caryophyllaceae. Pollen sets of contemporaneous coprolites and sediments show similarity in some cases, and different ratio or composition in some others. The similarities found between coprolites and sediments allow to infer that pollen in coprolites reveals the dominant vegetation taxa; on the contrary, a greater abundance of certain pollen types in coprolites than in sediments could be due to the fact that pollen in coprolites is biased with over-representations of the items preferred by guanacos, whereas a greater abundance in sediments than in coprolites could be due to the fact that the ingested plants were not in their flowering period. The results of this work show the value of coprolites as palaeoenvironmental indicators, and it contributes data to the palaeoenvironmental reconstruction and to the guanacos' diet.
\end{abstract}

KEY WORDS: coprolites, camelids, palaeoenvironment, Patagonia, pollen.

\section{INTRODUCCIÓN}

Los coprolitos son heces fósiles deshidratadas o mineralizadas que se pueden encontrar tanto en contextos paleontológicos como en arqueológicos (Callen y Cameron 1960; Reinhard y Bryant 1992). En ellos es posible hallar inclusiones, componentes orgánicos que han sido ingeridos por el organismo, como granos de polen, tejidos vegetales, semillas, parásitos, diatomeas, fitolitos, fragmentos de huesos, ostrácodos, pelos, plumas, insectos, caracoles, trazas de ADN fósil -que pueden pertenecer al propio organismo o a los componentes ingeridos- (Reinhard et al. 2008), entre otros. Es factible recuperar e identificar las inclusiones y así obtener información acerca de aspectos ecológicos y culturales de las poblaciones pasadas, permitiendo particularmente abordar estudios de paleodietas, de parasitismo, de reconstrucciones paleoambientales $e$ inferir estacionalidad en el uso de los recursos
(Reinhard y Bryant 1992; Horrocks et al. 2003). Por otro lado, el estudio de las inclusiones también ofrece datos sobre la fisiología y la biología de los organismos (Rodríguez de la Rosa et al. 1998). De esta manera, la información obtenida a partir del análisis de los coprolitos es valiosa para la reconstrucción del pasado y para la arqueología en su interés por conocer la historia de las poblaciones humanas antiguas.

\section{Antecedentes}

Con respecto a los estudios polínicos en coprolitos - copropalinología -, existen antecedentes realizados en heces fósiles de diferente origen zoológico: de humanos, llamas, bóvidos extinguidos, hienas, loros, perros, ovejas, entre otros (D'Antoni y Togo 1974a, 1974b; Jones y Bonavía 1992; Edwards et al. 1995; Sutton y Reinhard 1995; Alcover et al. 1999; Carrión et al. 2001, 2004, 2005; Chaves y 
Reinhard 2003, 2006; Horrocks et al. 2003, 2008, Dean 2006, de Porras 2010).

Para interpretar el significado ecológico del contenido polínico de los coprolitos, es importante tener en cuenta el mecanismo de polinización que presentan los taxones encontrados en ellos. Existen cuatro mecanismos principales de polinización: a) por el viento, b) por un animal vector, c) por el agua y d) por autopolinización (Faegri e Iversen 1989). Estos mecanismos se correlacionan con la morfología de los granos de polen y con la abundancia de granos producidos. Por otro lado, influyen en la cantidad de granos depositados sobre el terreno y sobre la vegetación (Pearsall 2000). Las plantas que tienen polinización anemófila, es decir aquellas cuyo polen se dispersa por el viento, producen una gran cantidad de granos, generalmente entre $10.000-70.000$ granos por antera. Estos granos son solitarios y poseen una pared por lo general lisa o con pequeñas esculturas, característica que contribuye a que el polen sea aerodinámico. Por esta razón, granos de polen con dispersión anemófila pertenecientes a especies que no hayan sido consumidas por el animal, pueden estar incluidos en las heces como consecuencia de su depositación sobre las hojas de las plantas que sí fueron consumidas (Alcover et al. 1999). Por otro lado, las especies que tienen polinización entomófila, es decir aquellas cuyo polen se dispersa por insectos, producen baja cantidad de granos de polen, aproximadamente 1.000 granos o menos por antera y rara vez forman parte de la lluvia polínica. Estos granos presentan esculturas en la pared que le permiten su adherencia a los polinizadores. La presencia de tipos polínicos con este mecanismo de polinización, podría indicar el consumo tanto de polen o flores, como de semillas y frutos con granos de polen todavía adheridos a ellos (Pearsall 2000).

La copropalinología representa una alternativa al análisis polínico convencional para la reconstrucción de la vegetación, particularmente en zonas áridas donde no hay trampas de polen como turberas o lagos (Scott 2000). También, Chaves (2000) señala que el análisis polínico de coprolitos puede contribuir al conocimiento del clima del Holoceno y del paleoambiente regional, cuando no se encuentran granos de polen en muestras de sedimentos. Por otro lado, Carrión et al. (2004) describe a los coprolitos como buenos indicadores paleoambientales, dado que el espectro polínico de heces fósiles refleja la composición de la vegetación del área y ofrece además información acerca de la vegetación regional. Asimismo puede reflejar la vegetación de los ambientes visitados por los individuos, es decir el rango de acción del organismo estudiado (Carrión et al. 2001).

\section{El guanaco y su relación con los cazadores-recolectores}

El poblamiento de la Patagonia estuvo en relación con la presencia de camélidos. Así, hay indicios de que la explotación del guanaco (Lama guanicoe Müller 1776) se remonta hasta fines del Pleistoceno, habiendo sido utilizado como recurso alimenticio y como materia prima para la confección de artefactos (Musters 1969; Miotti y Salemme 1999). Este camélido constituyó uno de los principales recursos de subsistencia de las sociedades cazadoras - recolectoras que poblaron el interior de la Patagonia (Borrero 2001; De Nigris 2004).

El guanaco es un herbívoro generalista (Raedeke 1980) que puede consumir polen como parte de su alimento o el que está adherido al mismo. Es un rumiante que tiene hábito pasteador y ramoneador, características que explicarían, en parte, su amplia distribución y la gran adaptabilidad que presenta para vivir en diversos ambientes (Wheeler 1991). Se alimenta principalmente de los estratos herbáceo (sobre todo de gramíneas, juncáceas y ciperáceas) y arbustivo. Posee un rango de acción amplio que varía de acuerdo a las condiciones del lugar y a la época del año, oscilando entre 1.30 y 9 km2 (Burgi 2007).

Los estudios de restos zooarqueológicos en Patagonia, entre ellos los coprolitos, brindan información de los organismos del pasado y contribuyen en la reconstrucción del paleoambiente en donde las poblaciones humanas que habitaron la Patagonia durante el Holoceno organizaron sus modos de vida. Los objetivos de este trabajo son reconocer el aporte de los estudios polínicos de coprolitos para las reconstrucciones paleoambientales e identificar posibles ítems de la dieta de los guanacos que vivieron durante el Holoceno en el área del sitio Cerro Casa de Piedra 7 situado en el Parque Nacional Perito Moreno (PNPM, Santa Cruz). 


\section{DESCRIPCIÓN DEL ÁREA DE ESTUDIO}

El Cerro Casa de Piedra está ubicado en el área cordillerana del PNPM en el Noroeste de la provincia de Santa Cruz (Fig. 1). Es una elevación de origen volcánico emplazada en la cuenca del Río Roble y del Lago Burmeister. En su frente norte muestra una serie de aleros y cuevas, entre las cuales se encuentra el sitio Cerro Casa de Piedra Cueva 7 (CCP7) a $900 \mathrm{~m} \mathrm{snm}\left(47^{\circ} 57^{\prime} \mathrm{S}, 72^{\circ} 05^{\prime} \mathrm{O}\right)$. Este cerro está localizado en el ecotono del bosque subantártico - estepa patagónica. En la región existe un gradiente de precipitaciones que va desde cerca de los $600 \mathrm{~mm}$ en el oeste a los $400 \mathrm{~mm}$ anuales en el este. La temperatura media anual es menor a $4^{\circ} \mathrm{C}$ (Paruelo et al. 1998).

\section{Vegetación actual}

En el PNPM se encuentran representadas las Provincias Fitogeográficas Altoandina, Subantártica y Patagónica (Roig 1998). La vegetación comprende diferentes unidades: a) semidesierto de altura, con Empetrum rubrum (murtilla) conformando manchones densos en los sitios más reparados; b) bosques dominados por Nothofagus pumilio (lenga) y bosquetes de $N$. antarctica (ñire) y $N$. betuloides (guindo); c) matorrales de lenga; d) pastizales y estepas de Festuca pallescens (coirón dulce); e) estepas de Nardophyllum obtusifolium (mata torcida); f) matorrales de Chilliotrichum sp. (romerillo) o Nardophyllum obtusifolium y g) mallines con Caltha sagitatta (maillico) y ciperáceas (Mermoz 1998). El área próxima al sitio CCP7 se caracteriza por presentar pastizales húmedos y mallines, y estepas arbustivas de Nardophyllum obtusifolium (Asteraceae subfam. Asteroideae). Mancini et al. (2002), realizaron un estudio polínico actual de esta área y señalan que los conjuntos polínicos representan a las formaciones vegetales que se desarrollan en el área de estudio.

\section{Estudios arqueológicos y paleoecológicos} realizados en el sitio

El sitio CCP7 presenta una secuencia estratigráfica y de ocupación humana fechada entre ca. 10.690 años ${ }^{14} \mathrm{C}$ AP (Aschero et al. 2008) y 3.400 años ${ }^{14} \mathrm{C}$ AP (Civalero y Aschero 2003) (Fig. 2). Con

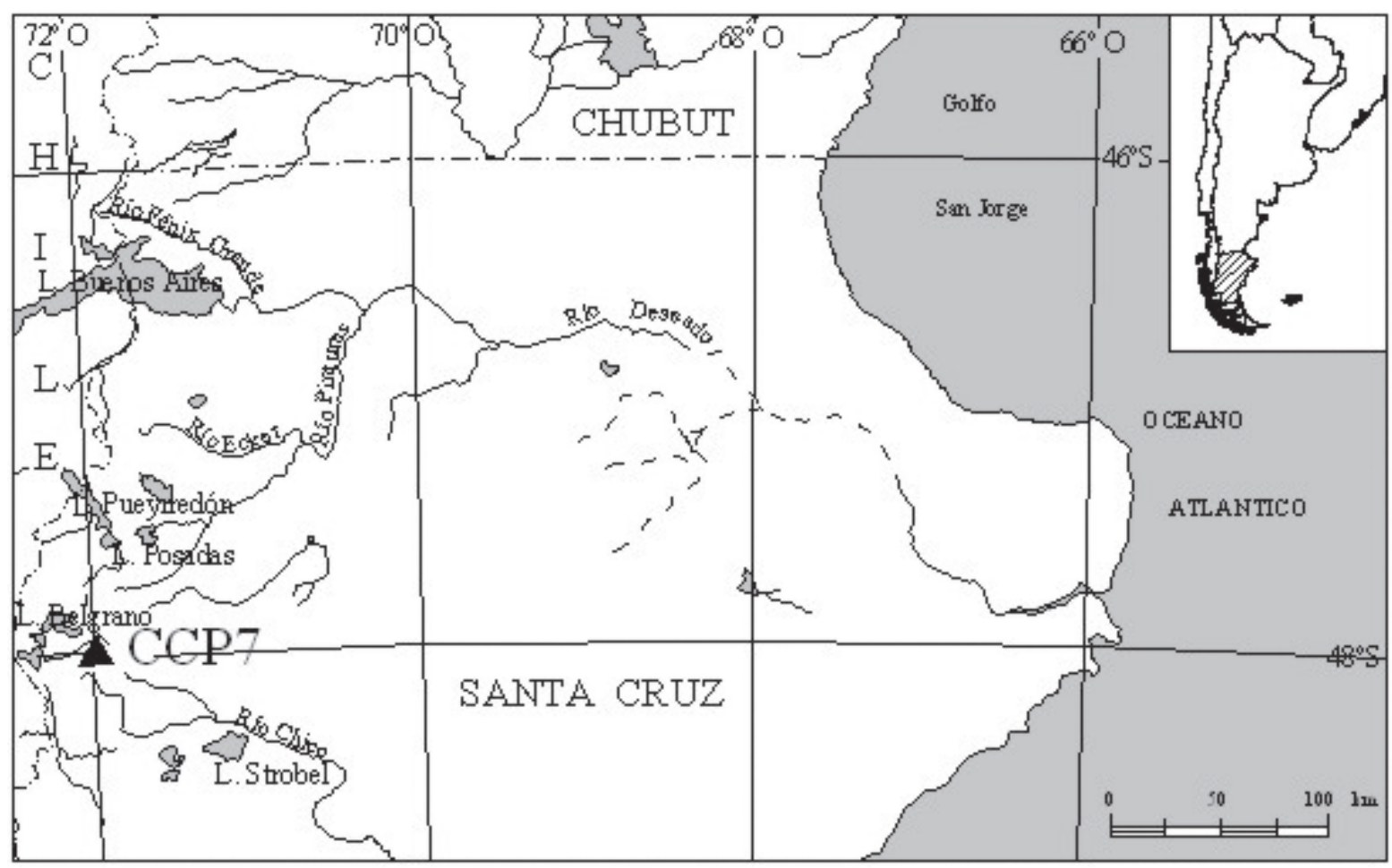

Fig. 1. Ubicación geográfica del sitio Cerro Casa de Piedra 7. 


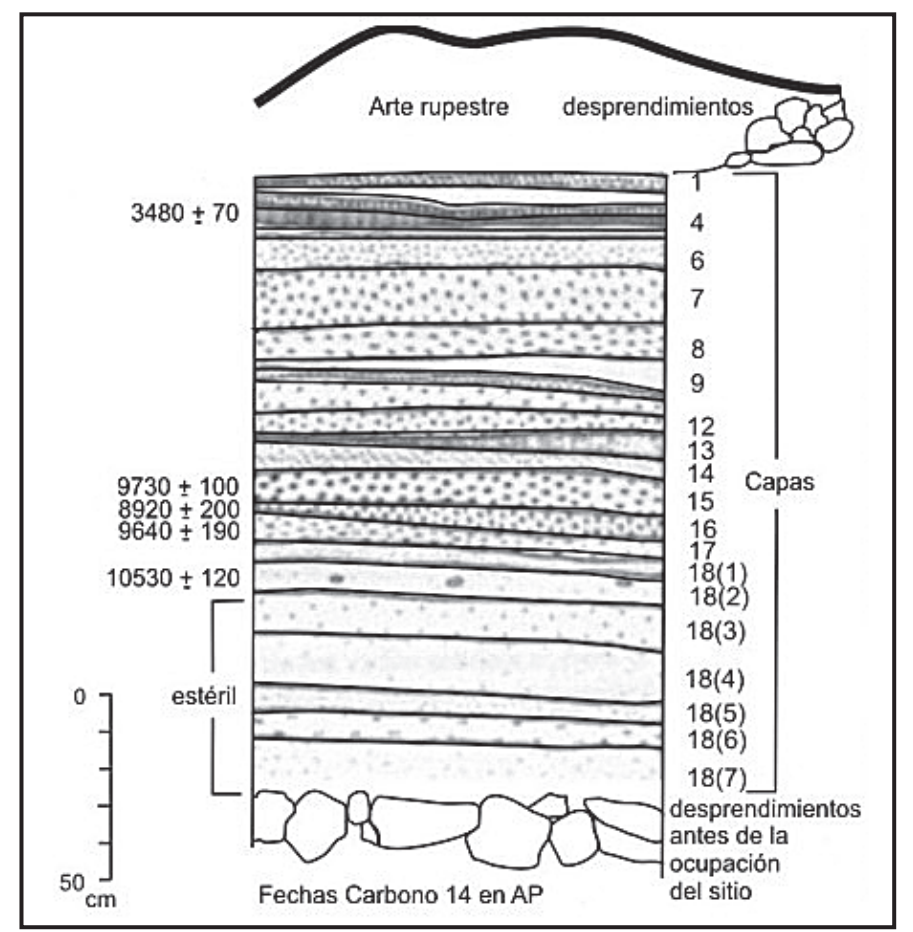

Fig. 2. Estratigrafía del sitio Cerro Casa de Piedra Cueva 7 y fechados radiocarbónicos (Extraído y modificado de Civalero y Aschero 2003).

anterioridad a ca. 3.400 años AP, el sitio conformaba un gran alero con un frente de aproximadamente 50 $\mathrm{m}$, emplazado en un área con relictos de bosques de Nothofagus, praderas con lagunas y cursos fluviales entre cerros y afloramientos rocosos (Aschero et al. 2005). Hacia ca. 3.400 años AP se produjeron episodios de caídas de bloques y desprendimientos que cerraron el sector oeste del sitio, provocando la finalización de depositación de sedimentos.

Sobre la base de estudios de tecnología lítica, Civalero y Aschero (2003) y Civalero y Franco (2003), sugirieron que las primeras ocupaciones fueron probablemente de cazadores - recolectores que se encontraban en un proceso de exploración $\mathrm{u}$ ocupación inicial de la cuenca de los lagos Belgrano/ Burmeister. Las evidencias arqueológicas indican que se han realizado actividades domésticas de carácter múltiple, con una marcada estructuración del espacio y una redundancia en la ocupación del sitio (De Nigris 2001). Entre estas evidencias se presentan manifestaciones de arte rupestre como negativos de manos y representaciones de guanacos (Aschero et al. 2005). Se ha registrado un nuevo fechado sobre carbones de $1.927 \pm 41$ años ${ }^{14} \mathrm{C}$ AP
(UGA 868) proveniente de un nuevo sector de la excavación arqueológica, que indicaría una ocupación ocasional del sitio más tardía a la propuesta anteriormente (Civalero et al. 2006).

Se han recuperado restos zooarqueológicos que corresponden a restos óseos y vellones de guanaco y huemul, siendo los restos de guanaco preponderantes sobre los de huemul (De Nigris 2004; Reigadas 2007). Además se ha registrado guano de diferente origen zoológico (De Nigris 2004). Las capas arqueológicas de ca. 9.000 años AP, presentan menor densidad de restos óseos que las capas más modernas, pero con elevados porcentajes de marcas de procesamiento en los huesos, indicando el consumo de estos recursos.

La meteorización ha tenido muy poca incidencia en los conjuntos óseos analizados (De Nigris 2004), debido a que este sitio es una gran oquedad con baja exposición a la luz solar y con condiciones de humedad y temperatura relativamente constantes, características que han posibilitado una preservación excepcional de los restos orgánicos, en particular de los materiales óseos (De Nigris 2004) y de los coprolitos. 


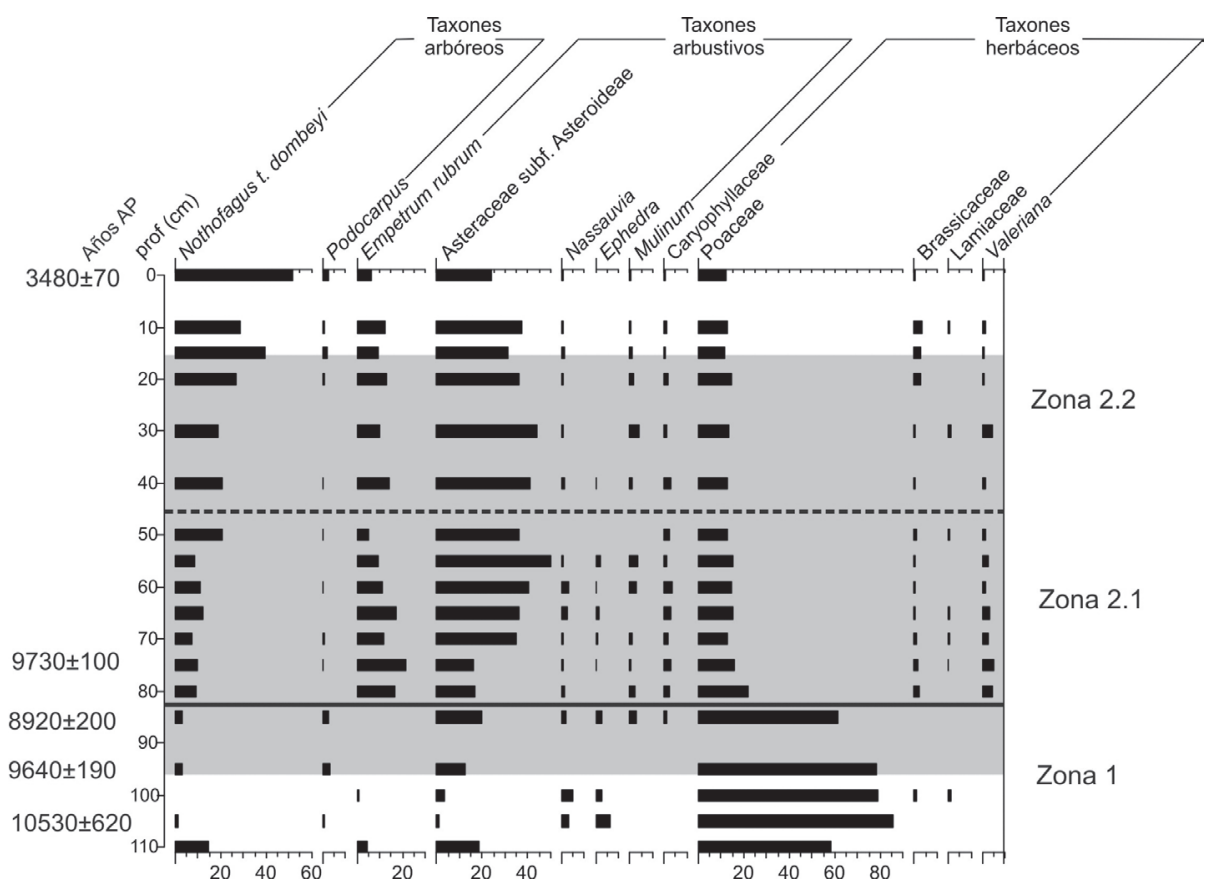

Fig. 3. Secuencia polínica del sitio Cerro Casa de Piedra Cueva 7 y fechados radiocarbónicos. La zona sombreada corresponde a la ubicación de las capas de donde proceden los coprolitos estudiados (Modificado de Mancini 2007).

Por otro lado, análisis palinológicos de los sedimentos minerales de la excavación arqueológica en el sitio, permitieron realizar una reconstrucción paleoambiental (Mancini 2007) (Fig. 3). En ese trabajo se obtuvieron dos zonas polínicas: una previa a ca. 9.000 años ${ }^{14} \mathrm{C}$ AP (Zona 1) y otra que comprende entre ca. 9.000 y 3.480 años ${ }^{14} \mathrm{C} \mathrm{AP}$ (Zona 2). Entre ambas zonas se registraron cambios importantes en la fisonomía de la vegetación del área, pasando del dominio de gramíneas, que indican condiciones de alta disponibilidad hídrica - Zona 1 -, a un aumento de los elementos de bosque, de taxones arbustivos y de plantas en cojín - Zona 2 -, que sugieren una mayor heterogeneidad de la vegetación con una composición similar a la que actualmente se desarrolla en el área.

\section{MATERIALES Y MÉTODOS}

En el sitio CCP7 se recuperaron numerosos coprolitos de diferente origen zoológico. En este trabajo se estudiaron 15 coprolitos de guanaco provenientes de 7 capas arqueológicas fechadas por ${ }^{14} \mathrm{C}$ entre $9.640 \pm 190$ años AP y $5.400 \pm 64$ años AP (Fig. 4).
El origen zoológico de los coprolitos fue determinado por la morfología, compatible con la de las heces de guanaco, y por la identificación de parásitos específicos de camélidos sudamericanos, como Eimeria macusaniensis, reportados en coprolitos de algunas de las capas arqueológicas de CCP7 (Fugassa et al. 2008; Taglioretti 2008; Velázquez et al. 2009).

Los fechados radiocarbónicos fueron calibrados con el programa Calib 5.0.1. Se observaron inversiones en las dataciones que podrían deberse a que las mismas se realizaron sobre diferentes

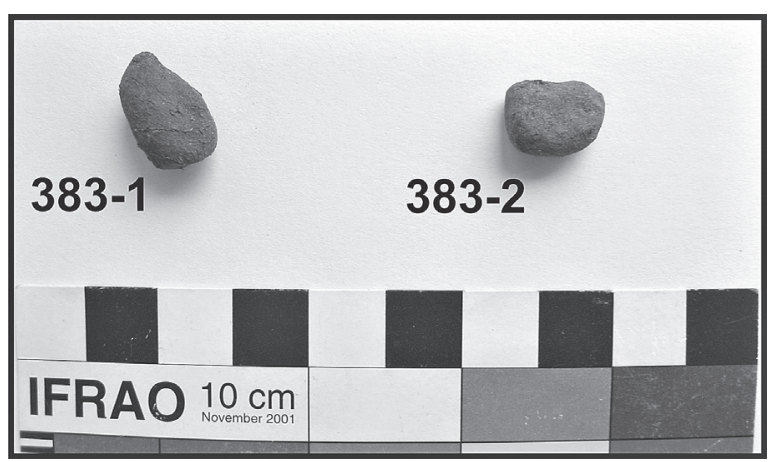

Fig. 4. Coprolitos de guanaco de CCP7. 
Tabla 1. Coprolitos, capas arqueológicas y fechados radiocarbónicos de los coprolitos analizados en este estudio.

* (Aschero 1996, Civalero y Aschero 2003, Aschero et al. 2008).

\begin{tabular}{|c|c|c|c|c|c|c|}
\hline Coprolito & Capa & $\begin{array}{c}\text { Material } \\
\text { datado }\end{array}$ & $\mathrm{N}^{\circ} \mathrm{Lab}$ & $\begin{array}{c}\text { Edad }^{14} \mathrm{C} \\
\text { (años AP)* }\end{array}$ & $\begin{array}{c}\text { Edad cal } \\
\text { (años AP) } \\
(2 \sigma)\end{array}$ & $\begin{array}{c}\mathrm{N}^{\circ} \text { de } \\
\text { coprolitos } \\
\text { estudiados }\end{array}$ \\
\hline $383-1$ & \multirow{2}{*}{5} & Óseo & UGA 866 & $5.400 \pm 64$ & 6.092-6.299 & \multirow{2}{*}{2} \\
\hline $383-2$ & & Tallo & LP 425 & $6.150 \pm 105$ & $6.778-7.270$ & \\
\hline M12-1 & \multirow{3}{*}{7} & Tallo & LP 374 & $5.610 \pm 110$ & $6.203-6.660$ & \multirow{3}{*}{3} \\
\hline M12-2 & & Óseo & UGA871 & $5.933 \pm 55$ & $6.640-6.896$ & \\
\hline M12-3 & & & (1) & & & \\
\hline M28-1 & \multirow{2}{*}{10} & \multirow{2}{*}{ Tallo } & \multirow{2}{*}{ LP 399} & \multirow{2}{*}{$8.380 \pm 120$} & \multirow{2}{*}{ 9.078-9.545 } & \multirow{2}{*}{2} \\
\hline M28-2 & & & & & & \\
\hline M11-1 & \multirow{3}{*}{$12 / 13$} & Tallo & LP 384 & $8.300 \pm 115$ & 9.018-9.499 & \multirow{3}{*}{3} \\
\hline M11-2 & & Madora & JGA 7381 & $7920+130$ & $8428-9037$ & \\
\hline M11-3 & & Madera & & & & \\
\hline M32-1 & 14 & Carbón & UGA 7382 & $8.460 \pm 400$ & $8.445-10.416$ & 1 \\
\hline M14-1 & \multirow{2}{*}{16} & \multirow{2}{*}{ Madera } & \multirow{2}{*}{ UGA 7383} & \multirow{2}{*}{$8.920 \pm 200$} & \multirow{2}{*}{$9.536-10.445$} & \multirow{2}{*}{2} \\
\hline M14-2 & & & & & & \\
\hline M16-1 & \multirow{2}{*}{17} & Carbón & LP 364 & $9.100 \pm 150$ & $9.768-10608$ & \multirow{2}{*}{2} \\
\hline M16-2 & & Madera & UGA 7384 & $9.640 \pm 190$ & $10.476-11.503$ & \\
\hline
\end{tabular}

materiales: carbón vegetal, tallo y material óseo provenientes de distintos microsectores de la cueva (Civalero y Aschero 2003; Mancini 2007; Aschero et al. 2008) (Tabla 1).

Los coprolitos se midieron, se separó la parte externa (submuestra E) de la interna (submuestra I), mediante el raspado del córtex con un bisturí, y se pesó cada submuestra. Luego se adicionó a cada submuestra una tableta de esporas de Lycopodium clavatum (Batch № 124961, media= 12.542 esporas/ tableta) como marcador foráneo (Stockmarr 1971) y para el cálculo de la concentración polínica (granos/ gramos de submuestra). Las submuestras se rehidrataron y filtraron a través de una malla de $260 \mu \mathrm{m}$.

En este estudio se trabajó sólo con las submuestras $E$ ya que en trabajos previos, en general no se encontraron diferencias significativas entre el contenido polínico de las submuestras E e I (Velázquez y Burry 2010).

El procedimiento de extracción polínica se realizó según D’Antoni (1979) y Faegri e Iversen (1989), y consistió en: a) concentración del filtrado por centrifugación; b) deshidratación con ácido acético puro y c) eliminación del material celulósico mediante acetólisis. Por último, se concentró el residuo obtenido mediante centrifugación y las submuestras se almacenaron en tubos Kahn con el agregado de 2 gotas de glicerina. Para el análisis microscópico se realizaron preparados semipermanentes.
La identificación y recuento de los granos de polen se llevó a cabo bajo microscopio óptico (con aumentos de 400X y 1000X). Se utilizó bibliografía especializada (Heusser 1971; Markgraf y D’Antoni 1978; Moore et al. 1991) y se empleó la colección de polen del Laboratorio de Palinología de la Universidad Nacional de Mar del Plata como referencia.

Durante la observación microscópica se contaron granos de polen, esporas y se registró la presencia de tejido vegetal y de restos de parásitos. La suma polínica incluyó a todos los tipos polínicos identificados y se expresó en porcentaje para estimar la frecuencia de cada uno de ellos.

Los resultados se graficaron en un diagrama polínico porcentual disociado, utilizando el programa estadístico TGView 2.02 (Grimm 2002). En el diagrama se representaron las submuestras externas de los coprolitos y las muestras de sedimentos contemporáneas a los coprolitos (Mancini 2007).

Se realizó un análisis de ordenación con los espectros polínicos de los coprolitos y de los sedimentos minerales pertenecientes a las mismas capas arqueológicas mediante el Análisis de Correspondencia Destendenciado utilizando el programa Tilia 1.12 (Grimm 1992). En este análisis se utilizaron sólo los tipos polínicos encontrados tanto en los coprolitos como en los sedimentos y que hayan presentado valores mayores al $2 \%$ de la suma polínica en al menos una muestra. 


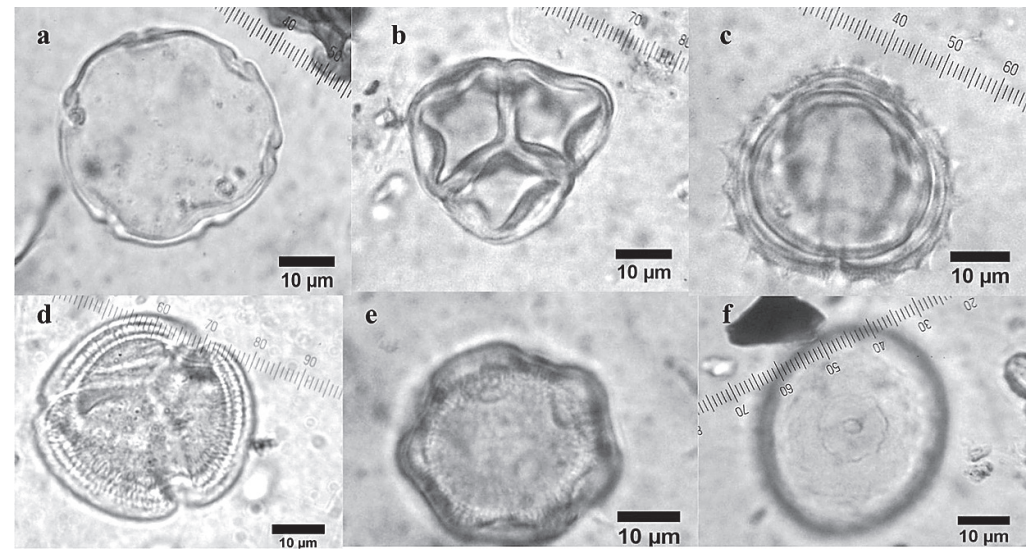

Fig. 5. Granos de polen hallados en coprolitos analizados de: a. Nothofagus, b. Empetrum rubrum, c. Asteraceae subfam. Asteroideae, d. Nassauvia, e. Caryophyllaceae y f. Poaceae

Con el objetivo de comparar estadísticamente el contenido polínico de los sedimentos y de los coprolitos de las mismas zonas polínicas descriptas en Mancini (2007), se calcularon las medianas de los porcentajes de los tipos polínicos dominantes para los sedimentos y para los coprolitos de cada zona. Luego se llevó a cabo el test no-paramétrico de Mann Whitney que permitió comprobar la existencia de diferencias significativas entre el contenido polínico de los coprolitos y los sedimentos para las mismas zonas polínicas.

\section{RESULTADOS}

Resultados palinológicos de los coprolitos

Los coprolitos presentaron granos de polen con muy buena preservación, lo que posibilitó una buena identificación polínica. En general, los tipos polínicos se identificaron a nivel de familia, en algunos casos a nivel genérico y en otros a nivel específico.

Se contaron entre 103 y 400 granos para cada una de las muestras analizadas. Se identificaron 23 tipos polínicos en total, y entre 5 y 11 taxones diferentes en cada coprolito. Entre los taxones encontrados los dominantes fueron: taxones arbóreos, característicos del bosque como Nothofagus, taxones arbustivos como Empetrum rubrum, Asteraceae subfam. Asteroideae y Nassauvia; y taxones herbáceos como Poaceae y Caryophyllaceae propios de la estepa (Figs. 5 y 6). Se observó una predominancia de los taxones arbustivos en todos los coprolitos analizados.
En el diagrama polínico (Fig. 6) se observan los espectros polínicos de los coprolitos y de los sedimentos contemporáneos a los coprolitos. En la mayoría de los coprolitos los tipos polínicos dominantes fueron Nothofagus, Empetrum rubrum, Asteraceae subfam. Asteroideae, Nassauvia, Caryophyllaceae y Poaceae. Se encontraron diferencias en cuanto a la abundancia de los tipos polínicos entre los coprolitos asociados a las capas más antiguas (capa 17: $9.640 \pm 190$ y capa 16: $8.920 \pm 200$ años AP) y los coprolitos asociados a las capas intermedias (capa 14: $8.460 \pm 400$, capa $12 / 13: 8.300 \pm 115 / 7.920 \pm 130$ años AP y capa 10: $8.380 \pm 120)$ y más modernas (capa 7: 5.610 \pm 110 y capa 5: 6.150 \pm 105 años AP).

Los más antiguos presentaron bajos o nulos porcentajes de Nothofagus (0-8\%), los más altos valores de Empetrum (12-93\%), altos valores de Asteraceae en la capa 17 (35 y 66\%), mientras que muy bajos en las capa 16 (0,5 y 2\%), y bajos valores de Poaceae (0-12\%). Los coprolitos pertenecientes a la capa 16, no presentaron granos de polen de Nothofagus sp. En particular, el coprolito 14-1 de la capa 16 presentó como tipos polínicos dominantes a Empetrum rubrum, Poaceae, Primulaceae y Valeriana, mientras que el 14-2, también de la capa 16, al tipo polínico Empetrum rubrum.

Los coprolitos asociados a las capas intermedias y a las más modernas mostraron mayores valores de Nothofagus (6-37\%), Nassauvia (1,5-31\%), Caryophyllaceae (hasta 19\%), Poaceae (hasta 16\%). Sin embargo presentaron un menor porcentaje de Empetrum rubrum (7,5-50\%). 


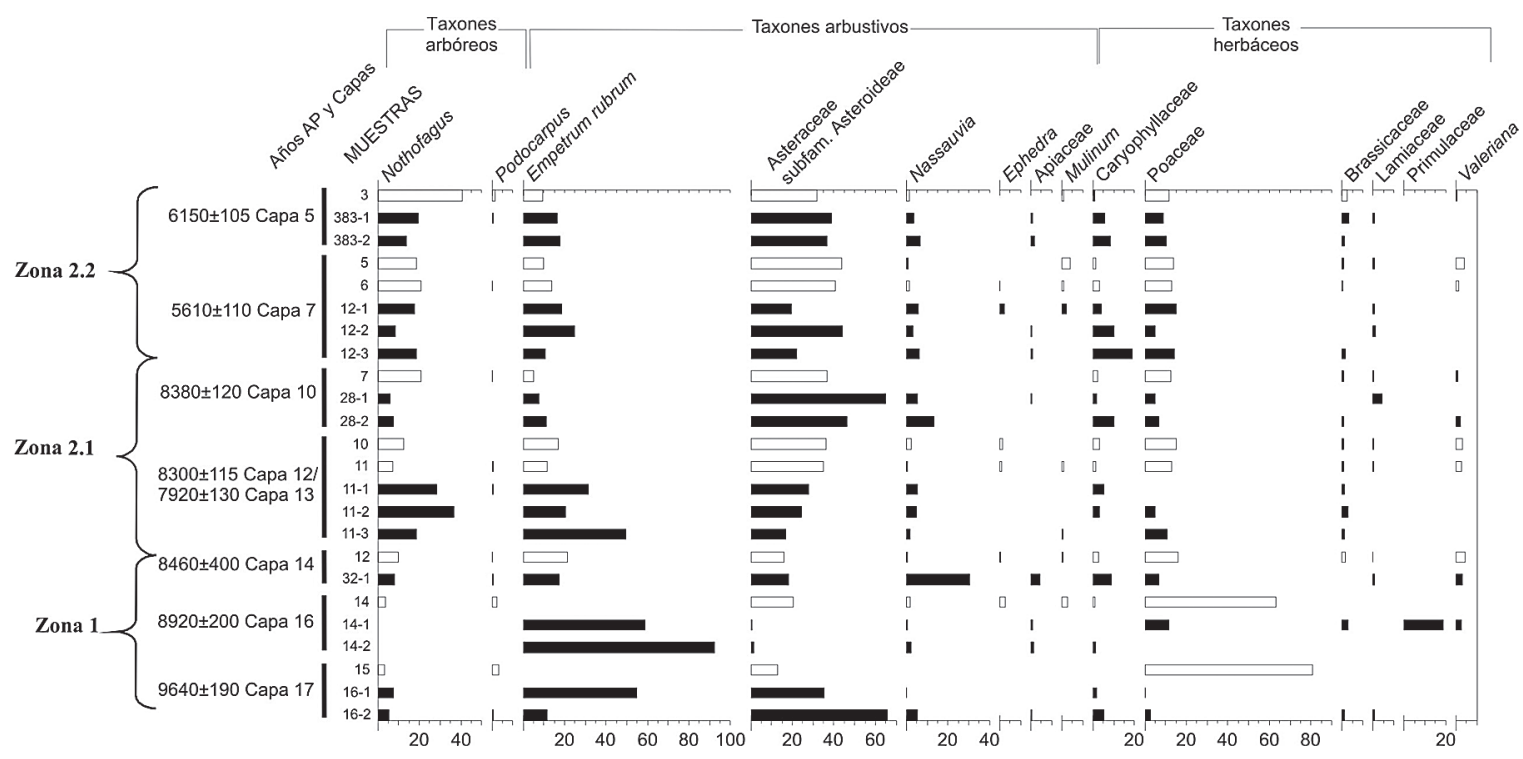

Fig. 6. Diagrama polínico porcentual de las submuestras externas de los coprolitos hallados en el sitio CCP7

( $\square$ ) y las muestras de sedimentos contemporáneos a los coprolitos ( $\square$ ). Zona 1, 2.1 y 2.2 corresponden a las zonas polínicas de la secuencia definidas en Mancini (2007).

Espectros polínicos coprolitos - sedimentos minerales

En las capas más antiguas $(9.640 \pm 190$ y $8.920 \pm 200$ años AP) se observó que los coprolitos y los sedimentos contemporáneos presentaban algunos tipos polínicos comunes: Asteraceae subfam. Asteroideae, Poaceae, Nothofagus, Nassauvia y Caryophyllaceae (Fig. 6). Sin embargo, los taxones más abundantes en las heces fósiles fueron Empetrum rubrum, Asteraceae subfam. Asteroideae que no coincidieron con los taxones con mayor proporción en los sedimentos contemporáneos. En los mismos se encontraron altos valores de Poaceae (60-80\%), mientras que nulos o muy bajos valores (0-12\%) en los coprolitos.

Por otro lado, la comparación entre los coprolitos de las capas arqueológicas intermedias y más modernas $(8.460 \pm 400,8.300 \pm 115 / 7.920 \pm 130$, $8.380 \pm 120,5.610 \pm 110$ y $6.150 \pm 105$ años AP) y los sedimentos reflejó una cierta similitud en la abundancia de los taxones Nothofagus, Asteraceae subfam. Asteroideae, Poaceae y el taxón Empetrum rubrum. Este último, en general, presentó valores mayores en los coprolitos que en los sedimentos contemporáneos (Fig. 6).
El Análisis de Correspondencia Destendenciado (DCA) realizado con los coprolitos y los sedimentos en forma conjunta, explicó con el eje 1 el 69,20 \% de la varianza y con el eje 2 el 20,15\% (Fig. 7a). Los conjuntos polínicos de coprolitos y sedimentos contemporáneos presentan similitudes en algunos casos y diferencias en proporciones o en composición en otros. Los coprolitos pertenecientes a las capas arqueológicas 5 y 7 están cercanos a los sedimentos contemporáneos mientras que los coprolitos y sedimentos de las capas 10 a 14 si bien se encuentran cercanos a lo largo del eje 1 se separan a lo largo del eje 2. Por otro lado, los coprolitos pertenecientes a las capas 16 y capa 17 están ubicados hacia la derecha del eje 1 y los sedimentos contemporáneos se ubicaron hacia el extremo izquierdo, indicando diferencias significativas entre los coprolitos y los sedimentos.

De acuerdo a la ordenación de los tipos polínicos (Fig. 7b) y a la abundancia de los mismos (Fig. 6), los taxones Nothofagus, Asteraceae subfam. Asteroideae y Caryophyllaceae son importantes en los coprolitos y sedimentos de las capas 5 y 7 , correspondientes a la zona polínica 2.2.

Los taxones Nassauvia, Caryophyllaceae, Lamiaceae y Asteraceae subfam. Asteroideae ex- 


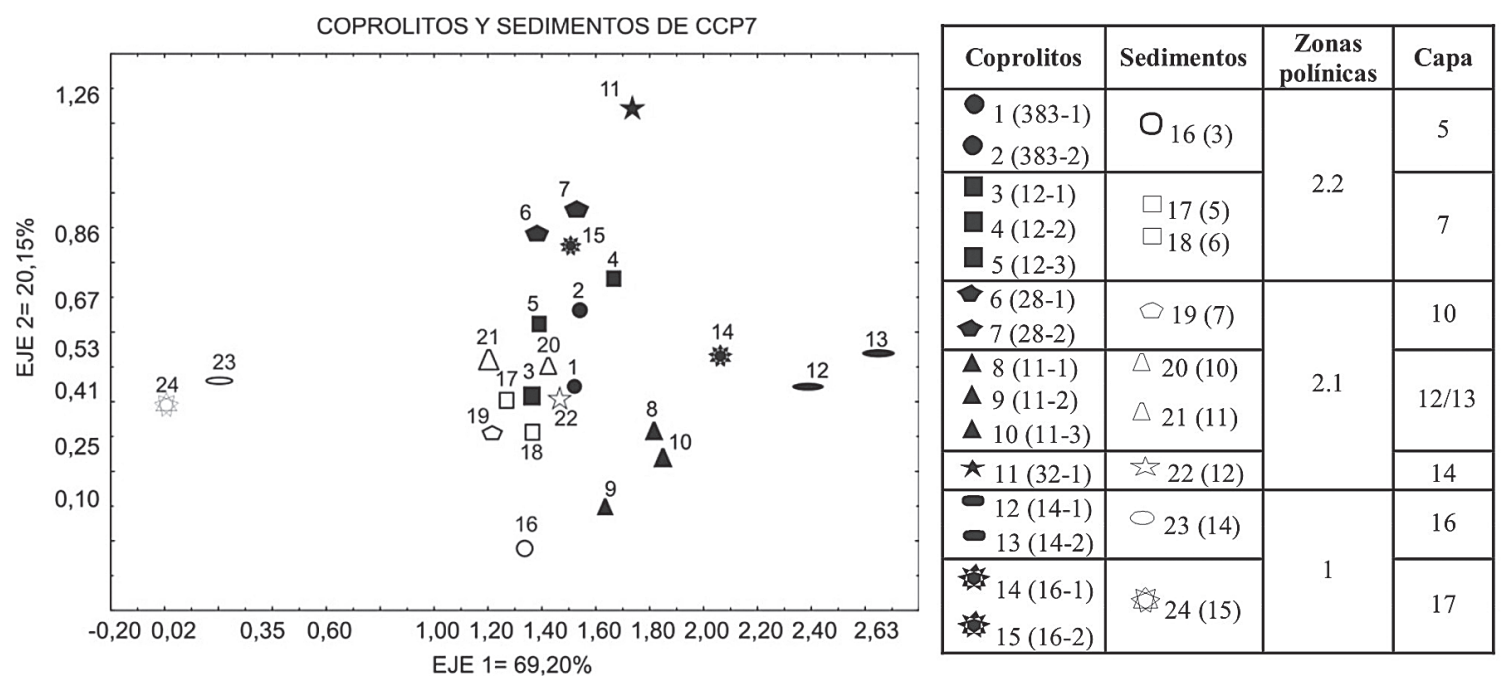

Fig. 7a. Análisis de Correspondencia Destendenciado de los coprolitos y de los sedimentos. Los números entre paréntesis corresponden a la denominación de los coprolitos y de las muestras de sedimento como se presentan en la figura 6.

plicaron la ordenación de los coprolitos de la capa 10. Los tipos polínicos Nothofagus y Empetrum rubrum definieron la disposición de los coprolitos asociados a la capa 12/13. Asimismo los tipos Nassauvia y Apiaceae explicaron la disposición del coprolito asociado a la capa 14. La ordenación de los sedimentos de las capas 10, 12/13 y 14 fue explicada por la disposición de Asteraceae subfam. Asteroideae. En las capas arqueológicas 10, 12/13 y 14 correspondientes a la zona polínica 2.1 se observaron similitudes en la composición pero no así en la proporción de los diferentes tipos polínicos entre los coprolitos y sedimentos.

Las muestras de sedimentos y coprolitos de las capas 16 y 17 (zona polínica 1) presentan diferencias en la composición de los conjuntos polínicos. Empetrum rubrum, Primulaceae y Asteraceae subfam. Asteroideae son importantes en los coprolitos mientras que Poaceae es importante en los sedimentos.

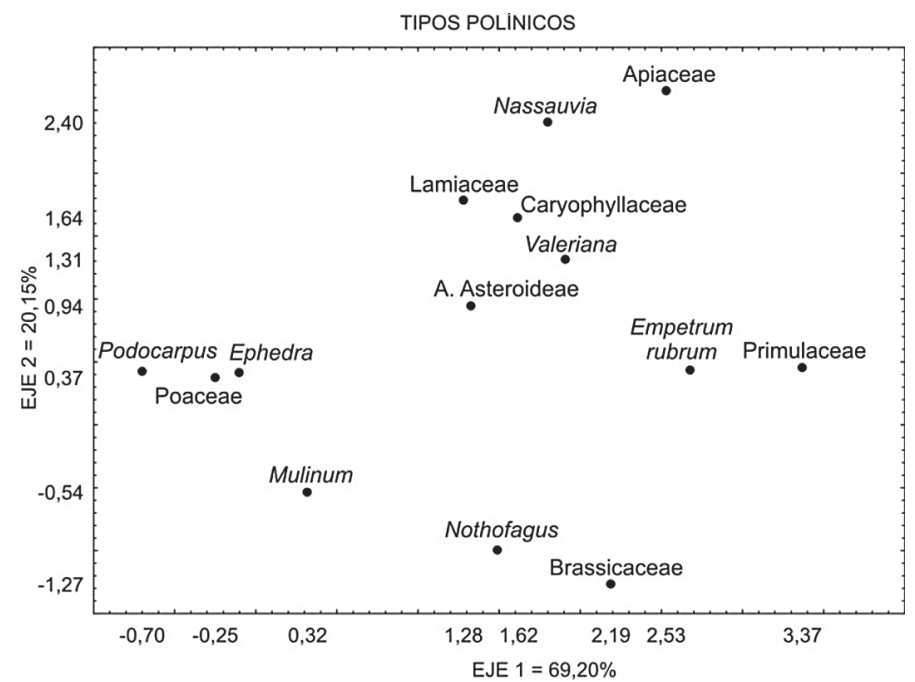

Fig. 7b. Análisis de Correspondencia Destendenciado de los tipos polínicos de los coprolitos y de los sedimentos. 
Tabla 2. Taxones entomófilos y anemófilos encontrados en los coprolitos posiblemente consumidos por los guanacos.

\begin{tabular}{|c|c|c|}
\hline Capa & Taxones entomófilos & Taxones anemófilos \\
\hline 5 & A. Asteroideae, Caryophyllaceae, Nassauvia & Empetrum rubrum \\
\hline 7 & A. Asteroideae, Caryophyllaceae, Nassauvia & Empetrum rubrum, Poaceae \\
\hline 10 & A. Asteroideae, Caryophyllaceae, Nassauvia & Empetrum rubrum \\
\hline $12 / 13$ & Caryophyllaceae, Nassauvia & Empetrum rubrum \\
\hline 14 & Caryophyllaceae, Nassauvia & Empetrum rubrum \\
\hline 16 & Primulaceae & Empetrum rubrum \\
\hline 17 & A. Asteroideae, Caryophyllaceae, Nassauvia & \\
\hline
\end{tabular}

Los tipos polínicos que presentaban mayor porcentaje en los coprolitos que en los sedimentos se consideraron como posibles ítems dietarios de los camélidos que habitaban en el área de CCP7 (Tabla 2). Cabe destacar que en la familia Asteraceae subfam. Asteroideae hay especies que pueden presentar dispersión anemófila o entomófila, sin embargo actualmente en el área de estudio crecen especies con dispersión entomófila (Nardophyllum obtusifolium y Senecio spp.), por lo que se las incluye dentro del grupo de taxones entomófilos.

Tabla 3. Tipos polínicos que presentaron diferencias significativas entre coprolitos y sedimentos $(\alpha=0,05)$ para cada Zona Polínica.

\begin{tabular}{|c|ll|}
\hline \multirow{2}{*}{ Zona Polínica 2.2 } & $\begin{array}{l}\text { Empetrum rubrum } \\
\text { Nassauvia } \\
\text { Caryophyllaceae }\end{array}$ & $\begin{array}{l}(p=0,0265) \\
(p=0,012)\end{array}$ \\
\hline Zona Polínica 2.1 & $\begin{array}{l}\text { Nassauvia } \\
\text { Poaceae }\end{array}$ & $\begin{array}{l}(p=0,0095) \\
(p=0,005)\end{array}$ \\
\hline \multirow{2}{*}{ Zona Polínica 1 } & $\begin{array}{l}\text { Empetrum rubrum } \\
\text { Poaceae }\end{array}$ & $\begin{array}{l}(p=0,03) \\
(p=0,032)\end{array}$ \\
\hline
\end{tabular}

La comparación de los promedios por zona polínica de los diferentes tipos polínicos encontrados en los coprolitos y en los sedimentos, realizado con el test de Mann-Whitney evidenció los taxones que presentaron diferencias significativas entre los porcentajes polínicos de los coprolitos y los sedimentos (Tabla 3).

\section{Otros restos encontrados en los coprolitos}

En los coprolitos 14 y 16 se identificaron restos de tejidos vegetales epidérmicos pertenecientes a Poaceae (Fig. 8a), además en el coprolito 14-2 se encontraron restos de Empetrum rubrum (Fig. 8b), de Osmorhiza y Armeria. Por otro lado entre los restos de parásitos se observaron huevos compatibles con Nematodirus sp. (Nematoda, Trichostrongylidae), huevos de Calodium sp. y Eucoleus sp. (Nematoda, Capillariidae) y ooquistes de Eimeria macusaniensis (Protozoa, Apicomplexa) (Fig. 8c). También se hallaron huevos deteriorados de tricostrongílidos y de capiláridos sin poder determinarse a nivel específico.
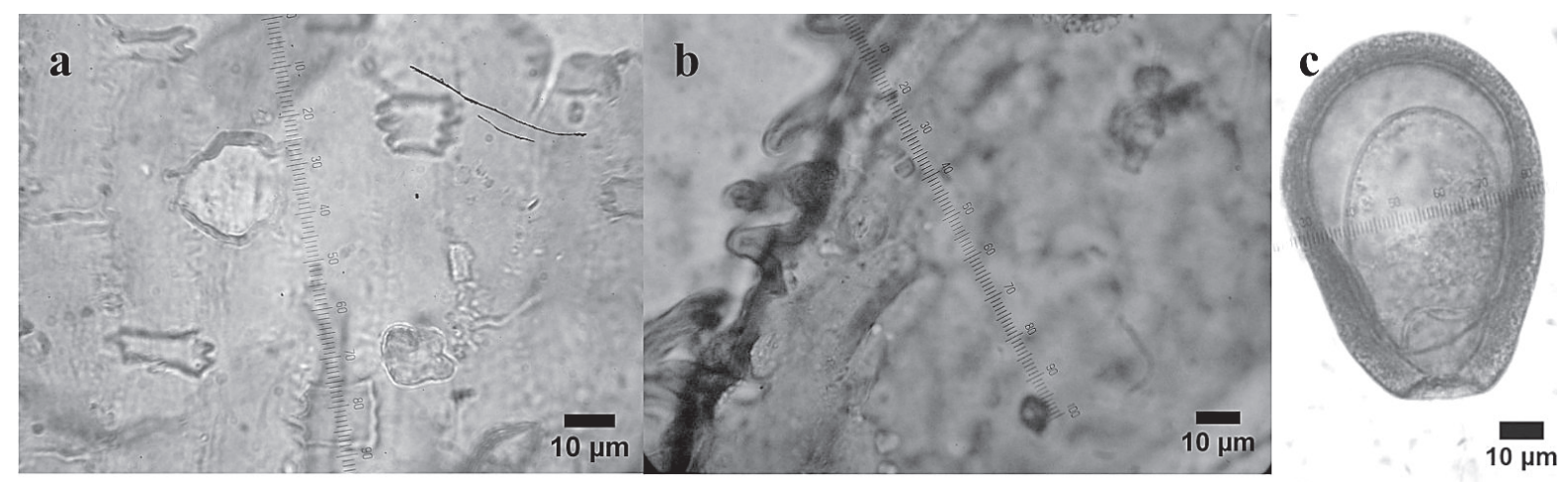

Fig. 8. Otros restos hallados en coprolitos analizados: a. Tejido epidérmico de Poaceae, b. Tejido epidérmico de Empetrum rubrum, c. Ooquiste de Eimeria macusaniensis. 


\section{DISCUSIÓN}

\section{Contenido polínico de los coprolitos}

Los granos de polen recuperados de los coprolitos presentaron una buena conservación lo que permitió su identificación. También D’Antoni y Togo (1974b), Reinhard y Bryant (1992), Chaves (2000) y Scott et al. (2003) manifestaron en sus respectivos trabajos la buena conservación del polen en los coprolitos.

Los coprolitos de CCP7 variaron en su composición polínica a lo largo del tiempo. Los cambios principales se dieron ca. $8.920 \pm 200$ años AP. Los más antiguos, correspondientes a las capas arqueológicas fechadas en $9.640 \pm 190$ años AP y $8.920 \pm 200$ años AP, presentaron dominancia de Empetrum rubrum. Esta especie es un subarbusto que crece en el semidesierto de altura y en sitios reparados. Mientras que los que presentaron los fechados posteriores mostraron abundancia de Nothofagus, Empetrum rubrum, Asteraceae subfam. Asteroideae, Nassauvia, Caryophyllaceae y Poaceae. El género Nothofagus, es un taxón característico del bosque mientras que los demás se encuentran en las estepas arbustiva y graminosa.

Entre los coprolitos más antiguos, los de la capa $16(8.920 \pm 200$ años AP) son los más singulares debido a la presencia de los tipos polínicos Valeriana y Primulaceae. En el caso del género Valeriana, por ejemplo Valeriana carnosa, crece en la estepa arbustiva (Mermoz 1998), mientras que Primulaceae es una familia que está asociada a lugares anegados dentro de valles (Soriano 1956) y en sectores reparados y húmedos.

\section{Coprolitos - sedimentos}

Las diferencias encontradas entre los coprolitos y los sedimentos más antiguos, zona polínica 1, están dadas principalmente por la diferente composición de los espectros polínicos. La gran abundancia de polen de Empetrum rubrum en los coprolitos y ausencia en los sedimentos y por el contrario el alto porcentaje de Poaceae en los sedimentos y bajo porcentaje en los coprolitos, podrían indicar la estacionalidad del coprolito que coincidiría con períodos en que las Poaceae no estarían en floración (ver Estacionalidad y dieta).
Por otro lado, las diferencias entre coprolitos y sedimentos pertenecientes a la zona polínica 2.1 se refieren a diferencias en la abundancia de los tipos polínicos, no así en la composición del espectro polínico. Mientras que en la zona 2.2, la más moderna de la secuencia, las diferencias entre coprolitos y sedimentos fueron menores, encontrándose similitudes en cuanto a la composición polínica y a la abundancia de los mismos, principalmente en los tipos Nothofagus, Asteraceae subfam. Asteroideae y Poaceae, indicando que estos coprolitos reflejan los taxones dominantes de la vegetación.

En este sentido, Carrión et al. (2004) sostienen que los coprolitos proporcionan datos suficientes para realizar inferencias paleoambientales. Precisamente, estos autores realizaron estudios en coprolitos de hienas -que presentan alimentación carnívora- y mostraron que en general, el espectro polínico es similar al de los sedimentos, reflejando así la lluvia polínica de la región. Por otro lado, Scott (1987) y Carrión et al. (2001) sugieren que el polen incluido en los coprolitos de hienas es producto de ingesta accidental, en relación a que proviene del consumo del contenido intestinal de las presas. En el presente estudio de coprolitos de guanaco, la interpretación es más directa debido a que el guanaco es herbívoro, se alimenta de distintas partes de las plantas y además estas plantas pueden estar "contaminadas" por la lluvia polínica. En consecuencia se puede precisar que el contenido polínico de los coprolitos debería reflejar la vegetación del área, sin embargo estos resultados pueden estar sesgados según la época del año en la que se depositaron los coprolitos.

\section{Estacionalidad y dieta}

No obstante las similitudes encontradas en general entre coprolitos y sedimentos, se reconocieron algunas diferencias en la abundancia de ciertos tipos polínicos. La mayor abundancia de un taxón particular en los sedimentos con respecto a los coprolitos, podría deberse a que las plantas consumidas no estaban en su período de floración. En otros casos la abundancia fue mayor en los coprolitos y puesto que el guanaco es un herbívoro generalista (Raedeke 1980) y ramoneador, que a menudo muestra un orden de preferencia entre las plantas que ingiere (Franklin 1982), cabe suponer que el registro polínico de los coprolitos está sesgado 
con sobrerrepresentaciones de los ítems preferidos por el guanaco.

De esta manera, las diferencias encontradas entre algunos coprolitos y los sedimentos contemporáneos, como por ejemplo para el tipo polínico Poaceae, que presentó mayor abundancia en los sedimentos (capas 16 y 17), permiten suponer que estos coprolitos provienen de momentos del año en que las gramíneas no se encontraban en su período de floración. En la estación invernal las heces tendrían bajas concentraciones polínicas (Velázquez 2009) debido al estado fenológico de las plantas, mientras que el registro polínico de los sedimentos, al estar compuesto por polen depositado durante todo el año y ser una mezcla de varios años, refleja la abundancia relativa de estas plantas. Asimismo, el alto porcentaje de Empetrum rubrum en los mismos coprolitos con respecto a los sedimentos contemporáneos, indicaría que existió selección de dieta por parte del guanaco que busca estas plantas aunque estén en baja proporción en el ambiente.

En cuanto al mayor porcentaje de Nassauvia en los coprolitos de las capas intermedias (capas 10, $12 / 13$ y 14) se sugiere que este taxón podría ser uno de los ítems dietarios del guanaco. En estas mismas capas, para Poaceae se observaron diferencias significativas, sin embargo el mayor porcentaje se encontró en los sedimentos.

Para los coprolitos de las capas más modernas (capas 5 y 7) se observaron diferencias significativas entre coprolitos y sedimentos en el porcentaje polínico de Empetrum rubrum, Nassauvia y Caryophyllaceae lo que sugiere que estos taxones podrían ser posibles ítems de la dieta de los guanacos.

Por otro lado, los estudios histológicos de restos de epidermis vegetales recuperados de los coprolitos, también aportan información para reconstruir la dieta de animales herbívoros y colaboran en la determinación de la estacionalidad de las deposiciones. Así fue que en uno de los coprolitos estudiados, 14-2 de la capa 16 , se encontraron estructuras epidérmicas con abundantes pelos glandulares propios de la epidermis de Empetrum rubrum (Correa 1999; Yagueddú com pers 2008), indicando que el organismo utilizó las hojas de esta especie como fuente alimentaria. Asimismo, la presencia de tejido epidérmico de Poaceae en los coprolitos más antiguos, 14 y 16 de las capas 16 y 17, demuestra que las gramíneas fueron fehacientemente consumidas y se descarta la hipótesis de ingestión de polen de manera accidental o por contaminación.

En aquellos coprolitos en los que se contó con polen y tejidos, particularmente de Empetrum rumbrum y Poaceae se puede suponer que uno de ellos, 14-2, corresponde al período otoño-invierno. La ausencia de Nothofagus, que florece en primavera, en los coprolitos de la capa 16 apoyaría la hipótesis de que estas heces corresponden al período otoño-invierno.

Con respecto al origen de los granos de polen de los coprolitos, Alcover et al. (1999) señalan que la abundancia en las heces de un taxón que produce pocos granos y que tiene baja dispersión de polen, significa que hubo ingesta intencional del taxón y que probablemente el mismo era muy importante en la dieta. Asimismo, Bryant y Holloway (1983) consideran que si el porcentaje de un taxón entomófilo excede un valor del $4 \%$ de la suma total de polen de los coprolitos, indica ingesta del taxón, ya que en los sedimentos el porcentaje de los tipos polínicos entomófilos rara vez supera este valor. Los tipos polínicos dominantes encontrados en los coprolitos con polinización entomófila fueron: Asteraceae subfam. Asteroideae Nassauvia, Caryophyllaceae, Valeriana y Primulaceae. Todos estos taxones, salvo el género Valeriana, presentaron mayor porcentaje en los coprolitos que en los sedimentos. Por otro lado, también los tipos polínicos dominantes hallados en los coprolitos que tienen polinización anemófila: Empetrum rubrum y Poaceae se consideraron como parte de la dieta. De esta manera se pudieron inferir los ítems dietarios pertenecientes a taxones entomófilos y anemófilos (Tabla 2). Así también los taxones anemófilos contribuyeron a caracterizar la lluvia polínica de la región.

La presencia de determinados tipos polínicos en los coprolitos también indica el rango de acción de los individuos. En este caso, todos los tipos polínicos encontrados, a excepción de Nothofagus, forman parte de comunidades esteparias, señalando el rango de acción de los guanacos predominantemente en la estepa. Por otra parte, la presencia de Nothofagus en los coprolitos, no indica la ingesta voluntaria, sino la posibilidad de que haya sido depositado por el viento sobre el alimento a ser consumido por el guanaco o sobre la superficie de las heces (Velázquez y Burry 2010). Igualmente la abundancia de polen de Nothofagus en los coprolitos coincide con las proporciones de los sedimentos minerales, 
permitiendo considerar a este tipo polínico, cuando está incluido en las heces, como un indicador paleoambiental sin estar sesgado por las preferencias de consumo del organismo.

El estudio de otras de las inclusiones de los coprolitos, que resistieron al procesamiento de extracción de polen, como los restos vegetales y los parásitos permite una aproximación más acabada de la dieta y de la biología de la fauna del pasado. Por esta razón se considera la necesidad de estandarizar el procesamiento de coprolitos para la extracción de diversos microfósiles, con el objetivo de sumar más líneas de evidencia en la resolución de la problemática abordada.

Para reforzar la interpretación paleoambiental que surge del análisis de los coprolitos, se sugiere agregar a este tipo de estudios, el análisis de heces actuales de guanaco para conocer los cambios en el contenido polínico que ocurren a lo largo del año.

\section{CONCLUSIONES}

Las inclusiones de los coprolitos de guanacos de CCP7 se encontraron en un buen estado de conservación, lo que facilitó la determinación polínica. La comparación con el contenido polínico de los sedimentos del mismo estrato evidencian la potencialidad que ofrecen los coprolitos como registros de la vegetación del pasado. Las diferencias cuantitativas entre los espectros polínicos de los coprolitos y de los sedimentos, tal el caso de Poaceae, y la presencia de tejido epidérmico de este mismo taxón, han permitido inferir la estacionalidad de algunos coprolitos y por ende la estacionalidad en el uso del sitio por parte de los camélidos.

Los resultados de este trabajo muestran en general el valor de los coprolitos como indicadores paleoambientales y en particular aportan datos para la reconstrucción paleoambiental y de dieta de los guanacos que vivieron en la región del Cerro Casa de Piedra durante el Holoceno.

\section{AGRADECIMIENTOS}

Agradecemos a María Teresa Civalero y a Carlos Aschero por proveernos las muestras para esta investigación y por la valiosa información brindada sobre el sitio. Nuevamente a María Teresa Civalero por la lectura crítica y los aportes a las versiones preliminares del manuscrito. A Cristina Yagueddú por haber realizado la identificación de los restos de tejidos vegetales. A Patricia Palacio por la asistencia en el procesamiento y en la confección de las figuras. Agradecemos a los evaluadores de la Revista por las sugerencias realizadas que permitieron mejorar el manuscrito. Este trabajo fue realizado gracias a la Comisión de Investigaciones Científicas de la provincia de Buenos Aires (CIC) y a subsidios de la Agencia Nacional de Promoción Científica y Tecnológica (PICTO 4-849) y de la Universidad Nacional de Mar del Plata (EXA 327/06).

\section{BIBLIOGRAFÍA}

ALCOVER, J. A. R., PEREZ-OBIOL, E. Yll y BOVER P. 1999. The diet of Myotragus balearicus Bate 1909 (Artiodactyla: Caprinae), an extinct bovid from the Balearic islands: evidence from coprolites. Biological Journal of the Linnean Society 66: 57-4.

ASCHERO, C. A. 1996. El área Río Belgrano-LagoPosadas (Santa Cruz): problemas y estado de problemas. En: Arqueología, Sólo Patagonia. Editado por: J. Gómez Otero, pp. 17-26. Puerto Madryn, Argentina.

ASCHERO, C., GOÑI, R. A., CIVALERO, M. T., MOLINARI, R., ESPINOSA, S. L., GURAIEB, A. G., y C. T. BELLELLI. 2005. Holocenic Park: Arqueología del Parque Nacional Perito Moreno. Anales de Parques Nacionales № XVII. 71-119.

ASCHERO, C. A., BOZZUTO, D., CIVAleRO, M. T., DE NIGRIS, M., DI VRUNO, A., DOLCE, V., FERNÁNDEZ, N., GONZÁLEZ, L. y M. SACCHI. 2008. Nuevas evidencias sobre las ocupaciones tempranas de Cerro Casa de Piedra 7. En: Arqueología de Fuego-Patagonia. Levantando piedras, desenterrando huesos... y develando arcanos. Editado por: F. Morello, A. Prieto, M. Martinic y G. Bahamondes. pp. 569-576. Centro de Estudios del Cuaternario Antártico (CEQUA). Punta Arenas, Chile.

BORRERO, L. A., 2001. El Poblamiento de la Patagonia. Toldos, milodones y volcanes. $1^{\underline{a}}$ Edición. Buenos Aires. Emecé. 200p.

BRYANT JR., V. M. y HOLLOWAY, R. G. 1983. The role of palynology in archaeology. En: Chaves, S. A. M. y K. J. Reinhard.

-2006. Critical analysis of coprolite evidence of medicinal plant use, Piauí, Brazil. Palaeogeographic, Palaeoclimatology, Palaeoecology 237: 110-118. 
BURGI, M. V. 2007. Radio de acción del guanaco (Lama guanicoe) en el NE de Chubut. Mastozoología Neotropical (14) 2: 285-291.

CALLEN, E. O. y T. W. M. CAMERON. 1960. A prehistoric diet revealed in coprolites. New Scientist 8: 35-40.

CARRIÓN, J. S., RIQUELME J. A., NAVARRO C. y M. MUNUERA. 2001. Pollen in hyaena coprolitos reflects late glacial landscape in southern Spain. Palaeogeographic, Palaeoclimatology, Palaeoecology 176: 193-205.

CARRIÓN, J. S., YII R.,. RIQUELME J. A y P. GONZÁLEZ. 2004. Perspectivas del análisis polínico de coprolitos y otros depósitos biogénicos útiles en la inferencia paleoambiental. Libro Homenaje a Emiliano Aguirre. Museo Arqueológico, 28-139.

CARRIÓN, J. S., GIL G., RODRÍGUEZ E., FUENTES N., GARCÍA-ANTÓN M. y A. ARRIBAS. 2005. Palynology of badger coprolites from Central Spain. Palaeogeography, Palaeoclimatology, Palaeoecology 226: 259-271.

CHAVES, S. A. M. 2000. Estudo palinológico de Coprólitos pré-históricos Holocenos coletados na toca do Boqueirão do sítio da Pedra Furada-contribuições paleoetnológicas, paleoclimáticas e paleoambientais para a região sudeste do Piauí-Brasil. Revista do Museu de Arqueología e Etnología, Universidade de São Paulo 10: 103-120.

CHAVES, S. A. M. y K. J. REINHARD, 2003. Paleopharmacology and Pollen: Theory, Method, and Application. Memorias do Instituto Oswaldo Cruz, Rio de Janeiro. Vol.98 (Suppl. 1): 207-211.

CHAVES, S. A. M. y K. J. REINHARD. 2006. Critical analysis of coprolite evidence of medicinal plant use, Piauí, Brazil. Palaeogeographic, Palaeoclimatology, Palaeoecology 237: 110-118.

CIVALERO, M. T. y C. A. ASCHERO. 2003. Early Occupations at Cerro Casa de Piedra 7, Santa Cruz Province, Patagonia Argentina. En: Ancient Evidence for Paleo South Americans: from where the south winds blow. Editado por: L. Miotti; M. Salemme y N. Flegenheimer, pp. 141-147. Center for the studies of the first American (CSFA) and A\&M University Press, Texas.

CIVALERO, M. T y N. V. FRANCO. 2003. Early human occupations in Western Santa Cruz Province, Southernmost South America. Quaternary international (109-110): 77-86.

Civalero, M. T., BOzZUTO, D. L., DI VRUNO, A. y DE NIGRIS, M. E. 2006. Cerro Casa de Piedra 7, una fecha reciente. Cuadernos del Instituto Nacional de Antropología y Pensamiento Latinoamericano 21. 259-261.
CORREA, M. N. 1999. Flora Patagónica parte VI. Dycotyledones Gamopétalas (Ericaceae a Calyceraceae). INTA. Provincia de Santa Cruz. Colección científica del INTA. Bs. As. 19-21.

D'ANTONI, H. L. 1979. Arqueoecología: El hombre en los ecosistemas del pasado a través de la Palinología. Colección Científica de Arqueoecología. México. 134 pp.

D’ANTONI, H. L. y J. TOGO. 1974a. Análisis polínico de los coprolitos humanos de Pampa Grande (Salta). Actas III Congreso Nacional de Arqueología. Montevideo. 1-8.

D’ANTONI, H. L. y J. TOGO. 1974b Análisis polínico de coprolitos animales: su aplicación en arqueología. Actas III Congreso Argentino de Arqueología. Salta. 1-16.

DE NIGRIS, M. E. 2001. Patrones de procesamiento final y consumo del guanaco en Patagonia. En: El uso de camélidos a través del tiempo. Editado por: G.L. Mengoni Goñalons; D.E. Olivera; H.D Yacobaccio. Ediciones Del Tridente. Buenos Aires. 9-28 p.

DE NIGRIS, M. E. 2004. El consumo en grupos cazadores recolectores: un ejemplo zooarqueológico de Patagonia Meridional. 1a ed. Sociedad Argentina de Antropología. Buenos Aires.

de PORRAS, M.E. 2010. Dinámica de la vegetación de la Meseta Central de Santa Cruz durante los últimos 11.000 años: forzantes bióticos y abióticos. Tesis Doctoral, Universidad Nacional de Mar del Plata, Argentina. 130 pp.

DEAN, G. W. 2006. The science of coprolite analysis: The view from Hinds cave. Palaeogeography, Palaeoclimatology, Palaeoecology 237: 67-79.

EDWARDS, D., SELDEN, P. A., RICHARDSON, J.B. y L. AXE. 1995. Coprolites as evidence for plant-animal interaction in Siluro-Devonian terrestrial ecosystems. Nature 377: 329-331.

FAEGRI, K. y J. IVERSEN. 1989. Textbook of Pollen Analysis. 4th ed. Faegri, K., P. E. Kalland y K. Krzywinski J. Wiley and Sons. Chichester. $328 \mathrm{pp}$.

FRANKLIN, W.L. 1982. Biology, ecology, and relationship to man of the South American camelids. En: Mammalian Biology in South America. Editado por: H. Mares y M. G. Genoways. University of Pittsburgh. Special Publication Series, Volume 6, pp. 457-488. Pymatuning. Laboratory of Ecology.

FUGASSA, M. H., SARDELLA, N. H., TAGLIORETTI, V., REINHARD, K., ARAÚJO, K. 2008. Morphometric variability in oocysts of Eimeria macusaniensis (Guerrero et al 1967) in archaeological samples from the Holocene of Patagonia, Argentina. Journal of Parasitology 94 (6): 1418-1420. 
GRIMM, E. 1992. Tilia software. Versión 1.1.2. Illinois State Museum. Research and Collection Center Springfield. Illinois.

GRIMM, E. 2002. TGView. Versión 2.02. Illinois State Museum. Research and Collection Center Springfield. Illinois.

HEUSSER, C. J. 1971. Pollen and Spores from Chile. Modern Types of Pteridophyta, Gymnospermae and Angiospermae. University of Arizona Press, Tucson. $167 \mathrm{pp}$.

HORROCKS, M., IRWIN G. J., MCGLONE M. S., NICHOL S. L. y L. J. WILLIAMS. 2003. Pollen, Phytoliths and diatoms in Prehistoric Coprolites from Kohika, Bay of Plenty, New Zealand. Journal of Archaeological Science 30: 13-20.

HORROCKS, M., SALTER, J., BRAGGINS, J., NICHOL, S., MOORHOUSE, R. y G. ELLIOTT. 2008. Plant microfossil analysis of coprolites of the critically endangered kakapo (Strigops habroptilus) parrot from New Zealand. Review of Palaeobotany and Palynology 149: 229-245.

JONES, J. G. y D. BONAVÍA. 1992. Análisis de coprolitos de llama (Lama glama) del precerámico tardío de la costa norcentral del Perú. Bulletin de l'Institut Français d'Études Andines 21 (3): 835-852.

MANCINI, M. V. 2007. Cambios paleoambientales en el ecotono bosque-estepa: Análisis polínico del sitio Cerro Casa de Piedra 7, Santa Cruz (Argentina). En: Arqueología de Fuego Patagonia. Levantando piedras, desenterrando huesos y develando arcanos. Editado por: F. Morello, M. Martinic, A. Prieto y G. Bahamonde. Ediciones CEQUA, pp. 89-94. Punta Arenas, Chile.

MANCINI, M. V., PAEZ, M. M. y A. R. PRIETO. 2002. Cambios paleoambientales durante los últimos 7.000 14C años en el ecotono bosque-estepa, 47-48오, Santa Cruz, Argentina. Ameghiniana. Revista Asociación Paleontológica Argentina 39 (2): 151-162.

MARKGRAF, V. y H. L. D'ANTONI. 1978. Pollen Flora of Argentina. Modern Spore and Pollen Types of Pteridophyta, Gymnospermae and Angiospermae. The University of Arizona Press, Tucson. 208 pp.

MERMOZ, M. 1998. Mapa preliminar de vegetación Parque Nacional Perito Moreno. Dirección Nacional de Conservación de Áreas protegidas. Delegación Regional Patagonia. Bariloche.

MIOTTI, L. y SALEMME, M. 1999. Biodiversity, taxonomic richness and specialists-generalists during Late Pleistocene/ Early Holocene times in Pampa and Patagonia (Argentina, Southern South America). Quaternary International 53/54: 53-68.
MOORE, P. D., WEBB J. A. y M. E. COLLINSON. 1991. Pollen Analysis. 2nd ed. Blackwell, London.

MUSTERS, G. 1969. La vida entre los Patagones. Editorial Solar-Hachete. Buenos Aires. 437 pp.

MÜLLER, P. L. S. 1776. Erste Classe, Säugende Thiere. En: Des Ritters Carl von Linné vollständiges Naturalsystem nach der zwölften Lateinischen Ausgabe, 1773-1776, pp. 1-62 +3 pls., Suppl. 384 pp, Register, 36 unnumbered pp. $+536 \mathrm{pp}$.

PARUELO, J. M., BELTRÁN, A., JOBBÁGY, E., SALA, O. E. Y GOLLUSCIO, R. A., 1998. El clima de la Patagonia: patrones generales y controles sobre los procesos bióticos. Ecología Austral 8 (2), 85-101.

PEARSALL, D. 2000. Paleoethnobotany. A handbook of procedures. Second Edition. Academic Press. 700 pp.

RAEDEKE, K. J. 1980. Food habits of the guanaco (Lama guanicoe) of Tierra del Fuego, Chile. Turrialba 30:177-181.

REIGADAS, M. 2007. Cazadores del Holoceno y los recursos faunísticos: Estudio de fibras animales de Cerro Casa de Piedra CCP5 y CCP7 (Santa Cruz). En: Arqueología de Fuego Patagonia. Levantando piedras, desenterrando huesos y develando arcanos. Editado por: F. Morello, M. Martinic, A. Prieto y G. Bahamonde. Ediciones CEQUA, pp. 89-94. Punta Arenas, Chile.

REINHARD, K. J. y V. M. BRYANT JR. 1992. Coprolite analysis: a biological perspective on archaeology. En: Archaeological Method and Theory 4, editado por Schiffer M.B. Tucson, AZ. University of Arizona Press. 245-288.

REINHARD, K. J., CHAVES, S., M., JONES, J. G. y A. M. IÑIGUEZ. 2008. Evaluating chloroplast DNA in prehistoric Texas coprolites: medicinal, dietary, or ambient ancient DNA? Journal of Archaeological Science 35: 1748-1755.

RODRÍGUEZ-DE LA ROSA R., CEVALLOS-FERRIZ R. S. y A. SILVA-PINEDA. 1998. Paleobiological implications of Campanian coprolites. Palaeogeography, Palaeoclimatology, Palaeoecology 142: 231-254.

ROIG, F. A. 1998. La vegetación de la Patagonia. En: Correa M (compaginador) Flora Patagónica. Colección Científica INTA. Tomo VIII, 1: 48-174.

SCOTT, L. 1987. Pollen analysis of hyaena coprolites and sediments from Equus Cave, Taung, southern Kalahari (South Africa). En: Scott, L., Fernández-Jalvo, Y., Carrión, J. y Brink, J. 2003. Preservation and interpretation of pollen in hyaena coprolites: taphonomic observations from Spain and southern Africa. Paleontología africana 39: 83-91. 
SCOTT, L. 2000. Pollen. En: Scott, L., Fernández-Jalvo, Y., Carrión, J. y J. Brink. 2003. Preservation and interpretation of pollen in hyaena coprolites: taphonomic observations from Spain and southern Africa. Paleontología africana 39: 83-91.

SCOTT, L., FERNÁNDEZ-JALVO, Y., CARRIÓN, J. y J. BRINK. 2003. Preservation and interpretation of pollen in hyaena coprolites: taphonomic observations from Spain and southern Africa. Paleontología africana 39: 83-91.

SORIANO, A. 1956. La vegetación de la República Argentina. IV. Los distritos florísticos de la provincia patagónica. Revista de Investigaciones Agrícolas. Ministerio de Agricultura y Ganadería. Instituto de Botánica Agrícola X (4): 321-357.

STOCKMARR, J. 1971. Tablets with spores used in absolute pollen analysis. Pollen et Spores 13: 615-621.

SUTTON, M. Q. y K. J. REINHARD. 1995. Cluster Analysis of the Coprolites from Antelope House: Implications for Anasazi Diet and Cuisine. Journal of Archaeological Science 22: 741-750.

TAGLIORETTI, V. 2008. Estudio paleoparasitológico de coprolitos de camélidos procedentes del sitio arqueológico Cerro Casa de Piedra 7 (CCP7), Patagonia, Argentina. Tesis de grado. Facultad de Ciencias Exactas y Naturales, Universidad Nacional de Mar del Plata.

VELÁZQUEZ N., J. 2009. Estudio palinológico en coprolitos de camélidos del Holoceno en el Noroeste de Santa Cruz, Argentina. Tesis de grado para optar el título de Licenciada en Ciencias Biológicas. Facultad de Ciencias Exactas y Naturales. Universidad Nacional de Mar del Plata. 77 pp.
VELÁZQUEZ, N., BURRY, L. S., PALACIO, P. y M. TRIVI. 2007. Estudio palinológico de coprolitos de camélidos del Holoceno en el NO de Santa Cruz. Actas del XVI Congreso Nacional de Arqueología Argentina. Tomo 2: 671-674. Jujuy, 8 al 12 de octubre de 2007.

VELÁZQUEZ, N., PALACIO, P., BURRY, L. S. Y M. TRIVI. 2008. Análisis palinológico de coprolitos de camélidos del Holoceno temprano (Cerro Casa de Piedra 7, Santa Cruz). Actas del I Congreso Nacional de Zooarqueología. Malargüe, 8 -12 de septiembre de 2008. 37 p.

VELÁZQUEZ, N., FUGASSA, M. y BURRY, L. S. 2009. Estudio polínico y paleoparasitológico de coprolitos de camélidos del Holoceno del sitio Cerro Casa de Piedra 7, Santa Cruz. En Bridges and Transitions, Abstracts, PAMinSA III. 114 p. Editado por: Suby J. A. y Guichón, R. A. III Paleopathology Association Meeting in South America. Necochea, Buenos Aires, Argentina, 14-16 de octubre de 2009.

VELÁZQUEZ, N. J. y BURRY, L. S. 2010. Estudio polínico de coprolitos de camélidos del Holoceno del sitio CCP7: Descifrando su información ¿dieta o contaminación polínica? En: Arqueología Argentina en el Bicentenario de la Revolución de Mayo. Editado por: R. J. Bárcena y H. Chiavazza. Tomo V, 2057-2063. XVII Congreso Nacional de Arqueología Argentina, Mendoza, 11-15 de octubre de 2010

WHEELER, J. C. 1991. Origen, evolución y status actual. En: Avances y perspectivas del conocimiento de los camélidos sudamericanos. Editado por: Fernández-Baca, S. 11-48. Oficina Regional de la FAO para América Latina y el Caribe, Santiago, Chile. 
